Ann. Génét. Sél. anim., I972, 4 (4), 599-6ог.

NOTE

\title{
UNE NOUVELLE ANOMALIE A ALLURE HÉRÉDITAIRE CHEZ DES AGNEAUX KHOUZISTANS
}

\author{
H. AMINI et D. BOZORG TCHAMI \\ Département de Zootechnie, \\ Faculté d'Agronomie de Jundi Shapur, \\ Ahwaz-Mollasani, Iran
}

\begin{abstract}
RÉSSUMÉ
Deux agneaux de même père, un mâle et une femelle avec un faible poids à la naissance et une croissance médiocre, un cou très court, un tronc raccourci et une queue adipeuse très petite et de forme carrée sont nés dans le troupeau expérimental de race locale de la Faculté d'Agronomie de Jundi Shapur, Khouzistan, Iran.

Ils présentent en outre souvent une légère météorisation et des difficultés de déplacement au pâturage.

Cette anomalie, non encore décrite, pourrait être de déterminisme héréditaire monofactoriel mendélien autosomal récessif.
\end{abstract}

Les moutons du Khouzistan (province du sud-ouest de l'Iran) sont très appréciés à cause de leur résistance à la grande chaleur estivale, qui peut attéfndre $53^{\circ} \mathrm{C}$ à l'ombre. Ils produisent une viande de bonne qualité, une certaine quantité de lait, et une láine moins grossière que celle des races des régions avoisinantes.

L'étude des caractéristiques de production's de ces moutons est en cours depuis près de deux ans, à la Faculté d'Agronomie de Jundi Shapur, à partir d'un troupeau expérimental constitué à partir de souches locales.

Au cours de l'agnelage d'automne 1971 deux animaux - un mâle (né simple) et une femelle (née double) - présentaient une série d'anomalies fort semblables.

D'un faible poids à la naissance, $2,8 \mathrm{~kg}$ pour le mâle (contre $3,9 \mathrm{~kg}$ en moyenne pour les contemporains d'agnelage) et $2,4 \mathrm{~kg}$ pour la femelle (contre $3,8 \mathrm{~kg}$ pour les contemporaines) 
ils avaient une croissance retardée. Ainsi, à l'âge de 4 mois le mâle ne pesait que $16,9 \mathrm{~kg}$ (contemporains : $27,4 \mathrm{~kg}$ ) et la femelle $10,50 \mathrm{~kg}$ (contemporaines : $26,2 \mathrm{~kg}$ ).

La forme du corps est modifiée principalement à cause d'un raccourcissement du cou ; cela donne aux deux animaux une allure "compacte" caractéristique (fig. I).

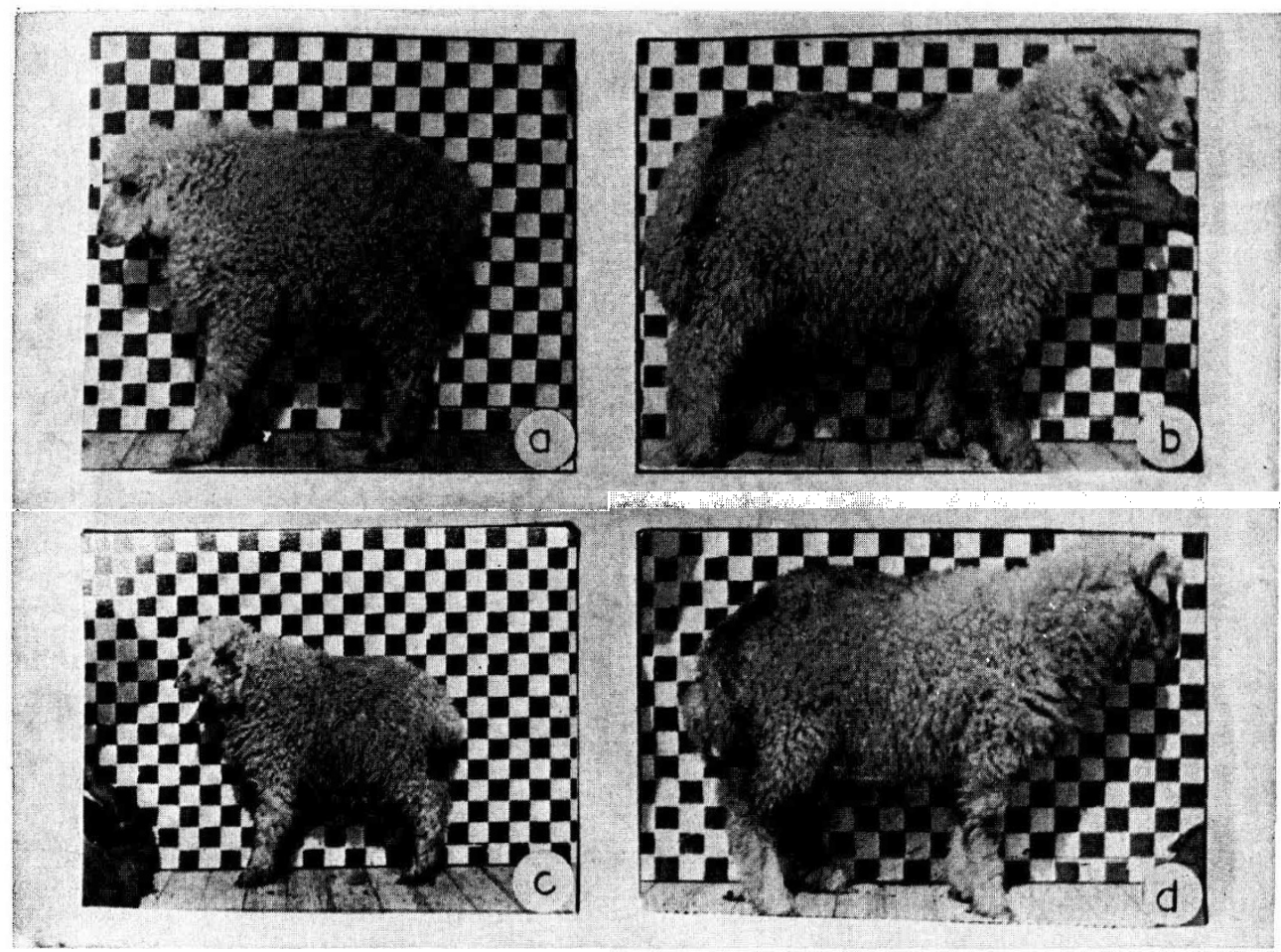

FIG. I. - Les deux agneaux anormaux: le mâle no 217 (a) et la femelle $n^{\circ} 216$ (c) comparés à des contemporains demi-frères ou sours du même agnelage no 218 (b) et 214 (d) à l'âge de 4 mois

Outre la miniaturisation de $2 \mathrm{r} 6$ et $2 \mathrm{I} 7$ on note l'allure caractéristique due à la réduction de la longueur relative du cou

La queue adipeuse, plus petite que celle des sujets normaux a, en outre, une forme plus carrée.

On note également une légère tendance à la météorisation et un comportement moins alerte au pâturage.

Ces deux agneaux ont le même père qui, comme leurs mères, sont parfaitement normaux ; on ne connaît malheureusement pas les liaisons de parenté entre leurs géniteurs.

A première vue cependant, on peut avancer l'hypothèse simple d'un déterminisme héréditaire mendélien monofactoriel, récessif, autosomal.

Un programme d'étude anatomique et génétique de l'anomalie a été mis en place.

Rę̧u pour publication en septembre 1972. 


\section{SUMMARY}

\section{A NEW ABNORMALITY APPEARING TO BE HEREDITARY IN KHUZISTAN LAMBS}

A male and female lamb were born of the same father in an experimental flock of local breed at the Faculty of Agronomy of Jundi Shapur, Khuzistan. Iran. They had low birth weight and mediocre growth, very short necks, shortened trunks, very small fatty tails and were square in shape.

The two lambs often presented slight meteorism and had difficulty in moving about in the pasture.

This abnormality, as yet undescribed, may be of a determinism which is hereditary, Mendelian, monofactorial, autosomal and recessive. 